\title{
Volatile constituents of tea stems (Camellia sinensis L.O. Kuntze) as semiochemicals to attract low country live wood termite, (Glyptotermes dilatatus Bugnion \& Popoff) in Sri Lanka
}

\author{
P.D. Senanayake ${ }^{1}$ K.M. Mohotti ${ }^{2}$ and P.A. Paranagama ${ }^{3 *}$ \\ ${ }^{I}$ Entomology Division, Tea Research Institute, Rathnapura. \\ ${ }^{2}$ Entomology Division, Tea Research Institute, Talawakelle. \\ ${ }^{3}$ Department of Chemistry, Faculty of Science, University of Kelaniya, Kelaniya.
}

Revised: 26 March 2015; Accepted: 28 May 2015

\begin{abstract}
Low country live wood termite (LCLWT), Glyptotermes dilatatus Bugnion \& Popoff is one of the major insect pests of low grown tea in Sri Lanka. The present study was aimed at investigating the chemical constituents and the attractant effects of tea stem volatiles isolated from different tea cultivars on the behaviour of alates of $G$. dilatatus. Volatile extracts of decayed and healthy stems of susceptible cultivars (TRI 2023, TRI 4042) and resistant cultivars (TRI 2027, TRI 4049) were collected. The attractant effects of stem extracts on termite alates were evaluated using the olfactometer bioassay. Volatile extracts of decayed stems obtained from the four tea cultivars were more attractive to alates than that of the healthy stems. The responses of alates to volatile extracts from decayed stems of TRI 2023, TRI 2027, TRI 4042 and TRI 4049 were $37 \pm 0.04,34 \pm 0.04,36 \pm 0.035$ and $32 \pm 0.04$, respectively whereas the responses of alates to volatile extracts from healthy stems TRI 2023, TRI 2027, TRI 4042 and TRI 4049 were $16 \pm$ $0.03,13 \pm 0.03,14 \pm 0.38$ and $16 \pm 1.5$, respectively.
\end{abstract}

The analysis of volatile extracts from decayed stems using Gas Chromatography-Mass Spectrometry led to the detection of 96 compounds in the four tea cultivars. Among them 15 compounds were common in all four tea cultivars and n-hexadecanoic acid and 9,12-octa decadienoic (Z,Z) acid were identified as the major constituents of decayed tea stems. Compound mono(2-ethylhexyl) phthalate was identified as the major constituent in healthy stem volatiles. Mono(2ethylhexyl) phthalate and n-hexadecanoic acid were present in both types of tea cultivars and they can be developed as an alternative method to control the test insect.

Keywords: Decayed stems, Glyptotermes dilatatus, olfactometer, volatile extracts.

\section{INTRODUCTION}

Plant semiochemicals are small organic compounds that act as chemical signals by producing a wide range of behavioural responses in insects. It is reported that volatile plant constituents influence the behaviour of the larvae or adult or both stages of insects. Volatile chemical compounds commonly act within a long distance from the emission source, while less volatile compounds act in a close range (Dethier et al., 1960). Plants may release hundreds of different compounds but only a very few trigger a behavioural response in insects and help to identify their host plants. A large number of attractive volatiles released by plants, and their combinations constitute a major challenge for herbivore insects to navigate towards their host plants. Interactions between the insect pests and semiochemicals of the host plants have been studied well and recognised as a communication system within insect species (Norduland \& Lewis, 1976). The use of host plant volatiles and insect pheromones have been successfully developed as an environmentally friendly pest control strategy to control economically important insect pests. It has been reported that volatile compounds produced by the host plant coconut attracts the red weevil (Rynchophorus ferrugineus), and this strategy is now employed in combination with the aggregation pheromone of red weevil as an alternative, eco-friendly method to control red weevil of coconut plantations in Sri Lanka (Gunawardana \& Swarnakanthi, 1995). Gunawardana and Dissanayake (2000) reported the isolation of volatiles, n-hexanal, n- hexanol, n-pentanol and cis-3-hexanol from the steam distillate of banana 
stems and investigated the synergistic effect of these compounds when blended with the pheromone. A trap has been developed to control the banana weevil Odoiporus longicollis.

Degradation of wood by termites is a continuing problem in many tropical and even some temperate regions of the world, resulting in serious economic impact on agriculture (Sands, 1977). Termites consume essentially the cellulosic material and wood decay fungi may provide nutritional benefits to termites by increasing the availability of cellulose and other nutrients (Getty \& Haverty, 1998). In a previous study, it was reported that Formosan subterranean termite, Coptotermes formosanus showed a strong preference for spruce saw dust infected with Marasmiellus troyanus (Murrill) Singer, over uninfected saw dust (Cornelius et al., 2002). An attractive substance (Z,Z,E)-3, 6, 8-dodecatrien-1-ol to the eastern subterranean termite, Reticulitermes flavipes was identified from the Western pine wood (Pinus monticola Dougl.) subjected to decay by the fungus, Lenzites trabea Pers. (Esenther et al,. 1961); it was found that this compound was analogous to the 'trail forming pheromone' of termites belonging to the Family Rhinotermitidae (Smythe et al., 1967). Amarasinghe et al. (2007) have reported that the bark of young tea stems produced six major volatile compounds namely, linalool, linalool oxide, phenyl acetaldehyde, methyl salicylate, geraniol and trans 2hexanal, which act as semiochemicals towards Xyleborus fornicatus (Coleoptera; Scolytidae). Holighaus and Schütz (2006) have reported the identification of thirteen volatile compounds of beech wood (Fagus sylvatica) decayed by the fungus, Nectria coccinea and several white rot fungi, which were semiochemicals towards Trypodendron domesticus $\mathrm{L}$. (Col., Scolytidae).

Low country live wood termite (LCLWT), Glyptotermes dilatatus Bugnion \& Popoff is one of the economically important major insect pests of tea in low country tea plantations (Cranham, 1966; Sivapalan \& Senaratna, 1981; Vitarana \& Mohotti, 2008) and it has been estimated that the yield loss due to LCLWT was $3000 \mathrm{~kg} / \mathrm{ha}$ made tea when the termite infestation reached up to $50 \%$ and stand for 10 years (Sands, 1977). The alates of LCLWT are attracted to decayed stumps, which is a result of invasion by the wood rot fungi through pruned stems of the tea plant, Camellia sinensis L.O. Kuntze (Balasooriya, 1998). A pair of alates first colonise in the decayed stump and continue feeding the healthy heartwood. The host plant does not show any external symptoms until the main trunk is fully colonised and the second generation alates start to emerge in dispersal (Vitarana \& Mohotti, 2008). High yielding tea varieties planted in low grown areas consisting of soft wooded frames that suffer extensive die back and rot after pruning increase the termite problem. Of the two types of high yielding tea cultivars, the susceptible cultivar is destroyed by termites within $10-15$ years, while the resistant cultivars survive about $30-40$ years (Sivapalan \& Senaratna, 1981).

The control of this pest is extremely difficult because of their concealed habit and social organisation, despite various integrated pest management (IPM) practices inclusive of agronomic, cultural and biological methods. Current recommendations for managing the LCLWT are restricted only to planting of tolerant cultivars, application of a wound dressing with fungicidal properties to protect prune cuts from decay and the removal of decayed wood at pruning to remove initial colonies (Advisory Circular, 2003). However, chemical and classical biological control methods are not efficient in the field (Dantanarayana \& Fernando, 1970; Vitarana, 1989). Hence, there is an urgent need to develop an environmentally friendly method that can be used to control the LCLWT in tea plantations.

Previous work carried out on the behaviour of LCLWT revealed that semiochemicals of the LCLWT have not been studied extensively. Among the few published reports, Samarasinghe et al.(1999) have reported the effect of volatile and non-volatile extracts of the decayed stems of tetmite resistant cultivar TRI 2027 and termite susceptible cultivars (TRI 2023 and 3063) against alates of LCLWT. The results indicated that susceptible cultivar TRI 2023 and resistant cultivar TRI 2027 were similarly attractive to termites. Highly susceptible cultivar, TRI 3063 was more attractive to alates than TRI 2023 and TRI 2027. A recent study was carried out on the behaviour of LCLWT against extracts of decayed and healthy stems of susceptible tea cultivars (TRI 2023, TRI 4042) and resistant cultivars (TRI 2027, TRI 4049) separately, and the results indicated that extracts obtained from decayed stems of each tea cultivar attracted the alates of LCLWT. Fractionation of the extract obtained from rotten tea stems has indicated that the chemical constituents in hexane fraction attract the alates of LCLWT than other polar fractions (personal communication). Hence the present study was aimed at analysing the volatile chemical constituents present in decayed and healthy stems of the resistant (TRI 2027, TRI 4049) and susceptible tea cultivars (TRI 2023, TRI 4042) in low country tea plantations, and compare the chemical constituents of the volatiles present in decayed and healthy stems of the four tea cultivars. Subsequently, the effects of host plant volatiles obtained from decayed and healthy stems of tea cultivars on the behavioural responses of LCLWT were explored. 


\section{METHODS AND MATERIALS}

\section{Insects}

Tea bushes infected with LCLWT were collected from St. Joachim Estate, Rathnapura (latitude 6 40 '58" N and longitude $80^{\circ} 23^{\prime} 57^{\prime \prime} \mathrm{E}$ and elevation $128 \mathrm{~m}$ amsl.) during the period 15 $5^{\text {th }}$ May 2011 to December 2011. Termite colonies in tea bushes were maintained in the laboratory in plastic boxes (Ca.12 L) at room temperature $\left(28 \pm 2{ }^{\circ} \mathrm{C}\right)$ at humidity conditions $(80 \%)$ under $12: 12 \mathrm{~L}: \mathrm{D}$ photoperiod to collect alates for bioassays.

\section{Collection and preparation of plant materials}

Samples of decayed and healthy stems from susceptible tea cultivars TRI 2023, TRI 4042 and resistant tea cultivars TRI 2027, TRI 4049 were collected separately and transported to the laboratory in clean polythene bags. Decayed tea stems and healthy tea stems were washed with distilled water to remove soil particles and air dried for $4 \mathrm{~h}$. Air dried samples were cut into small pieces before steam distillation.

\section{Extraction of volatiles}

Steam distillation was used for the extraction of volatile constituents in healthy and decayed stem pieces of tea cultivars TRI 2023, TRI 2027, TRI 4042 and TRI 4049 separately. The air dried pieces of tea stems $(500 \mathrm{~g})$ were steam distilled for $3 \mathrm{~h}$ and subsequently the condensed solution (1L) was extracted with $\mathrm{CH}_{2} \mathrm{Cl}_{2}(3 \times 100 \mathrm{~mL})$. Anhydrous $\mathrm{Na}_{2} \mathrm{SO}_{4}$ was added to the organic layer to remove water and evaporated using a rotary evaporator $\left(\mathrm{IKA}^{\circledR} \mathrm{RV} 10\right.$ Basic) at $35^{\circ} \mathrm{C}$ under reduced pressure. Dried extracts were transferred into pre weighed clean vials $(2 \mathrm{~mL})$ and the remaining solvent was removed under a stream of nitrogen. Dried extracts were stored in the refrigerator at $5{ }^{\circ} \mathrm{C}$ in glass vials until use for olfactometer bioassays and gas chromatography-mass spectrometry (GC-MS) analysis (Gunawardana \& Dissanayake, 2000).

\section{Evaluation of behavioural responses of LCLWT to volatile extracts in stems of tea cultivars}

The Y-tube olfactometer consists of a $12 \mathrm{~cm}$ long stem and two $10 \mathrm{~cm}$ long arms, each with a $2 \mathrm{~cm}$ inner diameter (Hoballah et al., 2002; Paranagama et al., 2002). The ends of the two tubes of the olfactometer were connected with perforated, transparent, wide mouthed glass bottles $(20 \mathrm{~mL})$ through the lids and the stem of the Y-tube was connected to a round bottom flask $(100 \mathrm{~mL})$, which was used to introduce the test insects. A constant airflow was maintained and the opening of the intersection of the arms facilitated the air circulation in the olfactometer. Two Whatman No. 1 filter papers $(1.5 \mathrm{~cm} \times 5 \mathrm{~cm})$ were used, one treated with a known amount of the extract dissolved in ethanol and the other treated with equal amount of ethanol $(100 \mu \mathrm{L})$. Both filter papers were air dried for $10 \mathrm{~min}$ to evaporate the solvent. The air dried filter papers were placed in the two plastic containers separately and the olfactometer was placed horizontally on a white background in day light. After switching on the vacuum pump, twenty test insects were introduced into the olfactometer. The number of alates that moved into the baited and unbaited containers within 30 min was recorded. At each trial the olfactometer was thoroughly cleaned with detergent, distilled water and acetone prior to use. Placement of the extract and the ethanol baited filter papers were interchanged randomly in subsequent replicates. The olfactometer was rotated $90^{\circ}$ at each replicate in a clockwise direction to control any directional effect. Test insects, filter paper strips and olfactometer were changed after each replication. All bioassays were carried out between $17-19 \mathrm{~h}$ and all experiments were replicated five times. From each extract $100 \mu \mathrm{g}$ doses were tested separately against alates of LCLWT. The responses of the alates were tested in the following volatile combinations.

(1) The extract of decayed stem of TRI 2023 vs. ethanol

(2) The extract of healthy stem of TRI $2023 \mathrm{vs}$. ethanol

(3) The extract of decayed stem of TRI $2027 \mathrm{vs}$. ethanol

(4) The extract of healthy stem of TRI $2027 v s$. ethanol

(5) The extract of decayed stem of TRI $4042 \mathrm{vs}$. ethanol

(6) The extract of healthy stem of TRI $4042 v s$. ethanol

(7) The extract of decayed stem of TRI $4049 \mathrm{vs}$. ethanol

(8) The extract of healthy stem of TRI $4049 \mathrm{vs}$. ethanol. To certify that ethanol has no effect on the behaviour of the test insect, a bioassay was performed with ethanol treated filter paper strip $v s$ a filter paper strip without any treatment.

\section{Gas chromatography-mass spectrometry (GC-MS) analysis}

The extracts obtained from steam distillation of the decayed and healthy tea stems of four tea cultivars TRI 2023, TRI 2027, TRI 4042 and TRI 4049 were used for the GC-MS analysis. The volatile extract of each tea cultivar was subjected to GC-MS analysis to identify the constituents in the extract. A Hewlett Packard 6890 series II chromatograph with a splitless injector $\left(220^{\circ} \mathrm{C}\right)$, flame ionisation detector (FID) $\left(270{ }^{\circ} \mathrm{C}\right)$, and a Rtx-Wax 
cross bond carbowax polyethylene glycol capillary column $(0.25 \mathrm{~mm} \times 0.25 \mu \mathrm{m} \times 30 \mathrm{~m})$ was used under the following conditions: initial temperature, $35^{\circ} \mathrm{C}(5 \mathrm{~min}), 35-280^{\circ} \mathrm{C}$ at $5{ }^{\circ} \mathrm{C} / \mathrm{min}$ and held for $10 \mathrm{~min}$ at $280^{\circ} \mathrm{C}$; the carrier gas used was Helium at a flow rate of $0.9 \mathrm{~mL} / \mathrm{min}$. The scan time and acquisition mass range of MS are $0.002 \mathrm{~s} /$ mass and $35-500 \mathrm{amu}$, respectively. For peak identification the mass spectral library Wiley W9N08 was used.

\section{Data analysis}

Data obtained from bioassays were transformed to Arc Sin values before performing ANOVA. Mean separation was performed by Tukey's Studentised test.

\section{RESULTS AND DISCUSSION}

\section{Extraction of volatiles}

Steam distillation of decayed and healthy stems of four tea cultivars gave a pale yellow oil with pleasant odour and the weight of volatile extracts obtained from the decayed stems of cultivars TRI 2023, TRI 2027, TRI 4042 and TRI 4049 were 16.2, 12.3, 16.8 and $12.0 \mathrm{mg}$, respectively. The weight of volatile extracts obtained from the healthy stems of cultivars TRI 2023, TRI 2027, TRI 4042 and TRI 4049 were 16, 13, 18 and $13 \mathrm{mg}$, respectively.

Evaluation of behavioural responses of LCLWT to volatile extracts in stems of tea cultivars

Alates of the LCLWT were exposed to a dose of 100 $\mu \mathrm{g}$ volatile extract obtained from decayed and healthy tea stems separately and the results are shown in Table 1. Statistical analysis of the results revealed that the responses of alates to extracts obtained from decayed and healthy cultivars were significantly different $(\mathrm{F}=93.61, \mathrm{df}=3$, $\mathrm{p}<0.0001)$ than that of ethanol. Mean separation among the extracts showed that volatile extracts of decayed stems were significantly higher than that of healthy stem extracts ( $p<0.05$, Tukey's mean comparison). There is no significant difference of the responses of alates among the tea cultivars of decayed or healthy stems $(\mathrm{F}=0.34$, $\mathrm{df}=3, \mathrm{p}=0.7931)$ and also between the two categories, resistant and susceptible $(\mathrm{F}=0.000, \mathrm{df}=1, \mathrm{p}=0.9897)$. Interaction effect between the cultivar and extract was not significant $(\mathrm{F}=0.79, \mathrm{df}=9, \mathrm{p}=0.6289)$ on the response of alates. Interaction effect between the two categories (resistance/susceptibility) of cultivars and extracts was also not significantly different $(\mathrm{F}=0.18, \mathrm{df}=3, \mathrm{p}=0.1510)$ on responses of alates, suggesting that volatile compounds of decayed stems contain compounds that attract alates of LCLWT irrespective of the resistance or susceptibility of the tea cultivar. These findings are in agreement with the findings of Samarasinghe et al. (1999), which revealed that the extract of decayed stems of cultivars TRI 2023 (susceptible cultivar) and TRI 2027 (resistant cultivar) are equally attractive to alates and the highly susceptible cultivar TRI 3063 is more attractive than TRI 2023 and TRI 2027. However in the present study, the volatile extract of highly susceptible tea cultivar TRI 3063 was not tested since it is no longer cultivated in low country tea plantations. The attractive effect of TRI 4042 and TRI 4049 has not been studied previously and the present study was focused on evaluating the effect of volatile extracts of the two new cultivars TRI 4042 and TRI 4049 against LCLWT in addition to TRI 2023 and TRI 2027. The responses of alates to healthy stem extract are significantly higher than the untreated control ( $p<0.05$, Tukey's mean separation). It could be due to the fact that some of the common compounds present in both decayed and healthy stems of tea and those compounds may be more attractive to alates than ethanol.

Table 1: Response of G. dilatatus to volatile extracts of tea stem of different cultivars of Camellia sinensis

\begin{tabular}{cccr}
\hline Tea cultivar & \multicolumn{3}{c}{ Percentage response \pm SE } \\
& Decayed stems & Healthy stems & EtOH \\
\hline TRI 2023 & & $16 \pm 0.03^{\mathrm{b}}$ & $3 \pm 0.02^{\mathrm{c}}$ \\
& $37 \pm 0.04^{\mathrm{a}}$ & & $7 \pm 0.02^{\mathrm{c}}$ \\
TRI 2027 & & $13 \pm 0.03^{\mathrm{b}}$ & $7 \pm 0.12^{\mathrm{c}}$ \\
& $34 \pm 0.04^{\mathrm{a}}$ & & $10 \pm 0.02^{\mathrm{c}}$ \\
& & $14 \pm 0.38^{\mathrm{b}}$ & $3 \pm 0.12^{\mathrm{c}}$ \\
TRI 4042 & $36 \pm 0.035^{\mathrm{a}}$ & & $4 \pm 0.12^{\mathrm{c}}$ \\
& & $16 \pm 1.5^{\mathrm{b}}$ & $6 \pm 0.29^{\mathrm{c}}$ \\
TRI 4049 & $32 \pm 0.04^{\mathrm{a}}$ & & $8 \pm 0.02^{\mathrm{c}}$ \\
\hline
\end{tabular}

Each data point represents the mean of five replicates. Mean numbers of insects response (\%) followed by same letters are not significantly different $(p<0.05)$ according to the Tukey's mean separation.

\section{GC-MS analysis of volatiles of decayed stem of tea}

Since the volatile extracts of decayed stems were more attractive to alates than that of healthy stems, an attempt was made to identify the chemical constituents of volatiles of the tea cultivars using GC-MS. Volatile compounds identified in decayed stems of tea cultivars TRI 2023, TRI 2027, TRI 4042 and TRI 4049 are presented in Table 2. GC-MS data comparison between the recorded and library mass spectra with similarity index higher than $95 \%$ and relative retention times were used for the identification of compounds in the four tea cultivars. At least 96 compounds were detected in decayed tea stems of which $43,50,36$ and 46 were identified as chemical constituents 
of volatiles present in TRI 2023, TRI 2027, TRI 4042 and TRI 4049, respectively (Table 2). The results indicated that a vast range of chemical constituents are present and among them long chain fatty acids, alcohols, carbonyls, esters, monoterpenes and sesquiterpenes are present as prominent group of compounds. Comparison of GC profiles of the decayed tea stem volatiles revealed that 15 compounds are common in all four tea cultivars (Table 3 ).

The constituents, $n$-hexadecanoic acid (palmitic acid) and 9,12-octadecadienoic acid (Z,Z) (linoleic acid) were identified as the two major constituents in decayed stems and the highest amounts of $n$-hexadecanoic acid (20.4\%) and 9, 12-octadecadienoic acid (Z,Z) (15.6\%) were observed in the decayed stem of TRI 4049. In addition to the presence of two major compounds in the volatiles of decayed tea stems, a higher percentage of mono(2-ethylhexyl) phthalate was present only in the decayed tea stems TRI $2023(8.76 \%)$ and TRI 4042 (9.7\%).

Volatiles of the healthy stems of tea cultivars TRI 2023, TRI 2027, TRI 4042 and TRI 4049 were also

Table 2: Chemical constituents and percentage of volatiles of the decayed stem of TRI 2023, TRI 2027, TRI 4042 and TRI 4049

\begin{tabular}{|c|c|c|c|c|c|}
\hline \multirow{2}{*}{$\begin{array}{l}\text { Retention } \\
\text { time }\end{array}$} & \multirow[b]{2}{*}{ Compound } & \multicolumn{4}{|c|}{$\%$ Total } \\
\hline & & $\begin{array}{c}\text { TRI } \\
2023\end{array}$ & $\begin{array}{c}\text { TRI } \\
2027\end{array}$ & $\begin{array}{c}\text { TRI } \\
4042\end{array}$ & $\begin{array}{r}\text { TRI } \\
4049\end{array}$ \\
\hline 9.720 & 2-Furan carboxaldehyde & 0.81 & 1.92 & & 1.48 \\
\hline 13.059 & 2 , propenoic acid, butyl ester & 1.2 & 1.07 & & 1.09 \\
\hline 14.496 & Benzaldehyde & & 0.69 & & \\
\hline 14.775 & 2-Furan carboxaldehyde,5-methyl & & 0.69 & & 0.58 \\
\hline 15.563 & Phenol & 0.86 & 0.95 & & 0.66 \\
\hline 15.702 & Ethanol, 2-[2-(2-methoxy ethoxy) ethoxy ]-acetate & & & 1.62 & \\
\hline 17.371 & Benzeneacetaldehyde & & 1.13 & & 0.97 \\
\hline 17.511 & Iso cineole & 1.22 & & & \\
\hline 17.928 & 1,8-Cineole & 0.65 & 0.7 & & \\
\hline 18.206 & 2-azabicyclo(2.2.1) heptanes & & 0.78 & & 1.53 \\
\hline 18.299 & 5,6-Dihydro-2Hpyran-2-one & 1.33 & & & \\
\hline 18.994 & Alpha terpinolene & 0.65 & & & \\
\hline 19.922 & n-Undecane & 0.67 & & & \\
\hline 20.246 & D-fenchyl alcohol & 0.68 & & 0.51 & \\
\hline 20.803 & Terpenene 1-ol & 2.45 & 1.26 & 1.45 & 1.4 \\
\hline 21.081 & Beta terpineol & 0.96 & 0.51 & 0.64 & 0.54 \\
\hline 21.545 & Benzene acetic acid, methyl ester & & 1.65 & & \\
\hline 21.638 & Bicyclo[2.2.1]heptan- 2-ol,1,7,7-trimethyl-exo & 1.28 & & & 0.84 \\
\hline 21.684 & Bicyclo[2.2.1]heptan-2-ol,1,7,7-trimethylEndo & & & 1.61 & \\
\hline 21.870 & 2-Butyl -1-octanol & & 1.23 & & \\
\hline 22.194 & Alpha terpineol & 3.22 & 1.7 & 2.3 & 1.71 \\
\hline 22.472 & 1-Dodecene & 1.63 & & & \\
\hline 22.658 & n-dodecane & 1.78 & 0.58 & 0.55 & 0.67 \\
\hline 23.353 & Benzaldehyde 4 methoxy & & 0.5 & 0.71 & 0.78 \\
\hline 23.446 & 2,6 -dimethyl undecane & 0.6 & & & \\
\hline 24.466 & Nonanoic acid & & 1.23 & 1.01 & 0.92 \\
\hline 24.513 & 2- methyl-dodecane & 1.92 & & & \\
\hline 24.930 & 2-methoxy-4-vinylphenol & 2.05 & 1.76 & 1.28 & 2.36 \\
\hline 25.208 & $\mathrm{n}$-Tridecane & 2.66 & 0.99 & 1.25 & 1.03 \\
\hline 26.182 & Phenol,2-methoxy-4-(2-propenyl) & & & 2.85 & \\
\hline 26.692 & Formamide,N-(2-methylphenyl) & 0.75 & & & \\
\hline 26.924 & Decanoic acid & & 1.05 & & \\
\hline 27.017 & 4- hydroxy-3-methoxy-Benzaldehyde (Vanillin) & 5.5 & & 2.35 & 3.31 \\
\hline 27.434 & 1- Tetradecene & 3.15 & 0.96 & 2.2 & 1.21 \\
\hline 27.620 & n-tetradecane & 1.2 & & 0.95 & 0.83 \\
\hline 28.269 & Phenol,2-methoxy-4-(1-propenyl)- (Z) & 0.55 & & & 0.56 \\
\hline 28.773 & 1,2,3,4-Tetramethoxybenzene & & 1.53 & & \\
\hline 29.196 & Ethanone,1-(4-hydroxy-3-methoxy phenyl)- & 1.36 & 0.58 & 1.51 & 1.55 \\
\hline
\end{tabular}

continued - 


\begin{tabular}{|c|c|c|c|c|c|}
\hline \multirow{2}{*}{$\begin{array}{l}\text { Retention } \\
\text { time }\end{array}$} & \multirow[b]{2}{*}{ Compound } & \multicolumn{4}{|c|}{$\%$ Total } \\
\hline & & $\begin{array}{c}\text { TRI } \\
2023\end{array}$ & $\begin{array}{c}\text { TRI } \\
2027\end{array}$ & $\begin{array}{c}\text { TRI } \\
4042\end{array}$ & $\begin{array}{r}\text { TRI } \\
4049\end{array}$ \\
\hline 33.694 & 2,6-dimethyl-7-octenylacetate & & & & 0.66 \\
\hline 33.741 & $2^{\prime}, 3^{\prime}, 4^{\prime}$, Trimethoxy acetophenone & & & 1.54 & \\
\hline 33.973 & 4-Butoxy-2,5,6,-trimethylpyrimidine & & 2.74 & & 0.68 \\
\hline 34.112 & Octadecanal & & 1.72 & & \\
\hline 34.436 & Tricyclo[4.3.1.1 $(3,8)$ undecan-1-ol & 1.07 & & 0.55 & \\
\hline 34.946 & $\begin{array}{l}\text { Tricyclo[4.3.0.0(7,9) nonene,2,2,5,5,8,8, } \\
\text {-hexamethyl 91.alpha.,6.beta., 7.A }\end{array}$ & & 0.71 & & \\
\hline 35.317 & n-tetradecanoic acid & 1.55 & 5.24 & 4.82 & 3.55 \\
\hline 35.549 & $\begin{array}{l}\text { 5'5-Epoxymethano-2,2,6-trimethyl-7 } \\
\text {-oxabicyclo[4.3.2]non-9-en-8-one }\end{array}$ & 2.05 & & & \\
\hline 35.735 & 1-Octadecene & 1.16 & & 0.74 & 0.53 \\
\hline 36.059 & Tetradecanal & & 1.2 & & \\
\hline 36.106 & Dyhydrocarvyl acetate & & & 1.33 & \\
\hline 36.569 & n-Pentadecanoic acid & & 0.76 & & 0.7 \\
\hline 36.755 & Caffeine & & 0.59 & & \\
\hline 36.987 & 2-Pentadecanone,6,10,14-trimethyl & & 0.86 & & \\
\hline 37.636 & 1,2-Benzenedicarboxylic acid, bis (2-methylpropyl) ester & 0.69 & 2.3 & 1.33 & 0.64 \\
\hline 38.331 & $\begin{array}{l}\text { 4-[(1Z)-(N-hydroxyethanimidoyl) } \\
\text {-2-methylpyridazin-3(2H)one/ }\end{array}$ & & 1.22 & & 0.88 \\
\hline 38.563 & 7,9-Di-tert-butyl-1-oxopiro(4,5) deca-6,9-diene-2,8-dione & 1.82 & 2.96 & 3.3 & \\
\hline 38.656 & Cis-9-hexadecenoic acid & & & & 2.75 \\
\hline 38.888 & n-hexadecanoic acid & 12.47 & 12.06 & 14.2 & 20.4 \\
\hline 39.120 & 1,2 Benzenedicarboxylic acid ,di butyl ester & 6.19 & & 8.62 & \\
\hline 41.392 & Octadecanoic acid methyl ester & 0.92 & & 0.61 & 0.65 \\
\hline 41.809 & 9,12-Octadecadienoic acid(Z,Z) & 9.76 & 9.58 & 6.74 & 15.6 \\
\hline 43.386 & Hexadecane,2,6,10,14,-tetramethyl & & 3.22 & & 0.94 \\
\hline 43.850 & Heneicosane & & 1.81 & & \\
\hline 44.453 & n-pentacos-3-ene & & 1.21 & & \\
\hline 45.334 & Benzyl butyl phthalate & & & & 1.09 \\
\hline 45.380 & 1,2 -Benzenedicarbxylicacid, butyl phenyl methyl ester & & & 1.34 & \\
\hline 45.797 & Hexanedioic acid, bis(2-ethylhexyl)ester & & & 4.65 & \\
\hline 46.632 & n-pentacosane & & & & 1.02 \\
\hline 47.096 & 12 -Methyl tricosane & & 1.09 & & \\
\hline 47.142 & n-heptadecane & & & & 0.71 \\
\hline 47.745 & 1,2-Benzenedicarboxylic acid, dicyclohexyl ester & 2.99 & 1.2 & 1.89 & 1.39 \\
\hline 48.116 & mono(2-ethylhexyl) phthalate & 8.76 & 2.61 & 9.7 & 3.91 \\
\hline
\end{tabular}

analysed by GC-MS and are shown in Table 4. Of the 55 compounds detected in healthy tea stems, 33, 15, 08 and 15 were identified from TRI 2023, TRI 2027, TRI 4042 and TRI 4049, respectively. According to the GC-MS analysis under the conditions described above, mono(2-ethylhexyl) phthalate was detected as the major component in TRI 2023 (27.77 \%), TRI 2027 (56.62 \%), TRI $4042(82.2 \%)$ and TRI 4049 (72.89\%). The results showed that the volatiles of healthy tea stems contained a complex mixture of numerous compounds, many of which are present in trace amounts. Unlike decayed tea stem volatiles, only three compounds, mono(2-ethylhexyl) phthalate, 1-hexadecene and n-hexadecanoic acid were common in all healthy stems of the four tea cultivars.
Although TRI 2027 showed the lowest percentage of the major constituent $(27.77 \%$ ), it had higher amounts of $n$-heptadecane (4.15\%), $n$-octadecane (5.26\%), nonadecane $(9.22 \%)$, eicosane $(4.76 \%)$, heneicosane $(5.19 \%)$, hexanedioic acid, bis 2-ethylhexyl ester $(17.4 \%)$ and benzenamine, 4-octyl-n-(4-octyl phenyl) (4.62\%), and there were comparatively small amounts in the volatile compounds present in healthy stem of other three tea cultivars. A comparison of decayed and healthy tea stem volatiles indicated that there is great variation in the chemical compositions of decayed and healthy tea stems as $n$-hexadecanoic acid is the major component in decayed tea stem and mono(2-ethylhexyl) phthalate is the major compound in healthy tea stem. The highest 
Table 3: Volatile constituents common in decayed stem extracts of the four tea cultivars TRI 2023, TRI 2027, TRI 4042 and TRI 4049

\begin{tabular}{lllllc}
\hline \multirow{2}{*}{$\begin{array}{l}\text { Retention } \\
\text { time }\end{array}$} & \multicolumn{1}{c}{ Compound } & \multicolumn{3}{c}{ \% Total } \\
& & TRI & TRI & TRI & TRI \\
& & 2023 & 2027 & 4042 & 4049 \\
\hline 20.803 & Terpenene 1-ol & 2.45 & 1.26 & 1.45 & 1.4 \\
21.081 & Beta terpineol & 0.96 & 0.51 & 0.64 & 0.54 \\
22.194 & Alpha terpineol & 3.22 & 1.7 & 2.3 & 1.71 \\
22.658 & n-dodecene & 1.78 & 0.58 & 0.55 & 0.67 \\
24.930 & 2-Methoxy-4-vinylphenol & 2.05 & 1.76 & 1.28 & 2.36 \\
25.208 & n-tridecane & 2.66 & 0.99 & 1.25 & 1.03 \\
27.434 & 1-Tetradecene (n-Tetradecene) & 3.15 & 0.96 & 2.2 & 1.21 \\
29.196 & Ethanone,1-(4-hydroxy-3-methoxy phenyl)- & 1.36 & 0.58 & 1.51 & 1.55 \\
31.329 & n-dodecanoic acid & 1.08 & 5.32 & 4.29 & 1.53 \\
35.317 & n-tertradecanoic acid & 1.55 & 5.24 & 4.82 & 3.55 \\
37.636 & 1,2-Benzenedicarboxylic acid, bis (2-methylpropyl) ester & 0.69 & 2.3 & 1.33 & 0.64 \\
38.888 & n-hexadecanoic acid & 12.47 & 12.1 & 14.2 & 20.4 \\
41.809 & 9,12-Octadecadienoic acid(Z,Z) & 9.76 & 9.58 & 6.74 & 15.6 \\
47.745 & 1,2-Benzenedicarboxlic acid,dicyclohexyl ester & 2.99 & 1.2 & 1.89 & 1.39 \\
48.116 & mono(2-ethylhexyl) phthalate & 8.76 & 2.61 & 9.7 & 3.91 \\
\hline
\end{tabular}

Table 4: Volatile constituents and percentage in healthy stems of tea cultivars TRI 2023, TRI 2027, TRI 4042, TRI 4049

\begin{tabular}{|c|c|c|c|c|c|}
\hline \multirow{2}{*}{$\begin{array}{l}\text { Retention } \\
\text { time }\end{array}$} & \multirow[b]{2}{*}{ Compound } & \multicolumn{4}{|c|}{$\%$ Total } \\
\hline & & $\begin{array}{c}\text { TRI } \\
2023\end{array}$ & $\begin{array}{c}\text { TRI } \\
2027\end{array}$ & $\begin{array}{c}\text { TRI } \\
4042\end{array}$ & $\begin{array}{r}\text { TRI } \\
4049\end{array}$ \\
\hline 14.265 & Ethanol, 2,2'-oxybis & & 2.06 & & 1.85 \\
\hline 21.406 & beta sinensal & 0.54 & & & \\
\hline 23.353 & Phenol, 2-methyl-5-(1- methyl ethyl) & 0.61 & & & 0.75 \\
\hline 25.765 & 1-(prop-1-enyl)-2-oxabicyclo[3.1.0] hexane & 1.45 & & & \\
\hline 25.579 & Benzaldehyde, 4 -hydroxy-3-methoxy (vanillin) & & 0.51 & & \\
\hline 25.997 & 2-Tetradecene, $(\mathrm{E})$ & & & & 3.08 \\
\hline 25.991 & 2-Butanone,4-(4-methoxyphenyl)- & & & & 0.41 \\
\hline 26.785 & Cis -Isoeugenol & 0.54 & & & \\
\hline 29.243 & Phenol, 2, 4-di-tert-butyl- & & 1.3 & & 2.41 \\
\hline 29.892 & Dodecanoic acid & 0.82 & 1.34 & & \\
\hline 30.124 & 3-methyl -5-(1,4,4-trimethyl-cyclohex & 1.22 & & & \\
\hline & -2-enyl-pent-2-enoic acid, ethyl ester & & & & \\
\hline 30.402 & 1- Hexadecene & 0.82 & 3.48 & 1.4 & 3.41 \\
\hline 31.654 & n-heptyl cyclohexane & 0.57 & & & \\
\hline 31.839 & 1-(3,5-Dimethoxy phenyl)pent 1 ene & & & & 0.53 \\
\hline 32.071 & Sulfurous acid, octadecylpentyl ester & 0.65 & & & \\
\hline 32.303 & 3-Heptadecene, (Z) & 0.68 & & & \\
\hline 32. 581 & n-heptadecane & 4.15 & & & \\
\hline 33.230 & Tetracosane,2,6,10,15,19,23-hexa methyl/Octyl phenol & 1.33 & 0.57 & & \\
\hline 33.648 & 2-propenyl-cyclohexane & 2.58 & & & \\
\hline 33.231 & Phenol-4-octyl & & 0.57 & & \\
\hline 33.833 & Tetradecanoic acid & & 6.46 & & \\
\hline 33.880 & Heptadecane, 2-Methyl & 0.86 & & & \\
\hline 34.251 & 9-Eicosane (E) & & 3.64 & & \\
\hline 34.436 & n-Octadecane & 5.26 & & & 2.39 \\
\hline 35.085 & Caffeine & & 0.64 & & \\
\hline 35.132 & Hexadecane,2,6,10,14-tetramethyl & 3.8 & & & \\
\hline 35.549 & Cyclohexane,2-propenyl- & 2.58 & & & \\
\hline
\end{tabular}

continued - 


\begin{tabular}{|c|c|c|c|c|c|}
\hline \multirow{2}{*}{$\begin{array}{l}\text { Retention } \\
\text { time }\end{array}$} & \multirow[b]{2}{*}{ Compound } & \multicolumn{4}{|c|}{$\%$ Total } \\
\hline & & $\begin{array}{c}\text { TRI } \\
2023\end{array}$ & $\begin{array}{c}\text { TRI } \\
2027\end{array}$ & $\begin{array}{c}\text { TRI } \\
4042\end{array}$ & $\begin{array}{r}\text { TRI } \\
4049\end{array}$ \\
\hline 36.152 & Phthalic acid, isobutyl nonyl ester & & 0.67 & & \\
\hline 36.198 & Nonadecane & 9.22 & & & \\
\hline 36.569 & n-hentriacontane & 1.61 & & & \\
\hline 37.404 & n-hexadecanoic acid & 11.01 & 16.2 & 6.7 & 1.45 \\
\hline 37.590 & 1,2-Benzenedicaboxylic acid, butyl 2-methylpropyl ester & & & & 2.01 \\
\hline 37.868 & Eicosane & 4.76 & & & 2.03 \\
\hline 39.246 & 1,2-Benzenedicaboxylic acid, di butyl ester & & & 5.8 & \\
\hline 39.491 & Heneicosane & 5.19 & & & \\
\hline 40.418 & 9,12-Octadecadienoic acid (Z,Z) & & 4.15 & & 0.96 \\
\hline 40.511 & Nonahexacontanoic acid & 4.04 & & & \\
\hline 40.975 & 1-Docosene & & & & 1.24 \\
\hline 43.850 & Cyclotetracosane & & & & 0.66 \\
\hline 44.360 & Hexane dioic acid, bis (2-ethylhexyl)ester & 17.4 & & & \\
\hline 45.241 & n-tetratetracontane & 1.77 & & & \\
\hline 46.493 & 1,2-Benzenedicaboxylic acid, mono (2-ethylhexyl) ester & 27.77 & 56.62 & 82.2 & 72.89 \\
\hline 46.539 & n-hexatriacontane & 1.58 & & & \\
\hline 47.745 & Pentatriacontane & 1.98 & & & \\
\hline 48.950 & Docosane & 1.25 & & & \\
\hline 51.362 & Benzenamine,4-octyl-n-(4-octyl phenyl) & 4.62 & & & \\
\hline 52.196 & Aspidofractinine,17-methoxy-3-methylene-,(2.alpha.alpha) & 0.54 & & & \\
\hline 56.045 & Alpha spinasterone & & 0.74 & & \\
\hline 60.822 & $\begin{array}{l}\left(2 \mathrm{R}^{*}, 8 \mathrm{aS}\right)-1 \text {-Benzyl-3(E) benzalidene-4-methyl } \\
\text {-2-phenyl 1,2,3,5,67,8,8a-octa. }\end{array}$ & 0.91 & & & \\
\hline 61.244 & Unknown 1 & & & 0.7 & \\
\hline 61.540 & Unknown 2 & & & 0.5 & \\
\hline
\end{tabular}

Table 5: Common compounds present in the volatiles of healthy stems of TRI 2023, TRI 2027, TRI 4042, TRI 4049

\begin{tabular}{lcccc}
\hline \multirow{4}{*}{ Compound } & \multicolumn{4}{c}{$\%$ Total } \\
& TRI & TRI & TRI & TRI \\
& 2023 & 2027 & 4042 & 4049 \\
\hline mono(2-ethylhexyl) phthalate & 27.77 & 56.62 & 82.2 & 72.89 \\
1- hexadecane & 0.82 & 3.48 & 1.4 & 3.41 \\
Hexadecanoic acid & 11.01 & 16.2 & 6.7 & 1.45 \\
\hline
\end{tabular}

amount of mono(2-ethylhexyl) phthalate was reported in the tea cultivar TRI 4042 (82.2\%). A different composition of compounds was detected in decayed and healthy stem volatiles. $n$-hexadecanoic acid was identified as the common compound in decayed and healthy volatiles of tea stems. The identification of chemical composition of volatiles in tea stem has not been reported before. Although Samarasinghe et al. (1999) had obtained the GC profiles of stem volatiles of TRI 2023 and TRI 2027, the chemical compositions of volatile fractions were not identified. Hence this is the first report on the identification of chemical composition of volatiles isolated from decayed and healthy stems of TRI 2023, TRI 2027, TRI 4042 and TRI 4049. The bioassay carried out with the volatiles of tea stem indicated that decayed tea stem volatiles are more attractive to the alates than healthy tea stem volatiles suggesting that $n$-hexadecanoic acid, linoleic acid and other compounds in decayed tea stem volatiles may be responsible for the attractant effect of the volatiles. It has been reported that Z, Z, E-3, 6, 8-dodecatrien-1-ol is an attractant substance to the eastern subterranean termite Reticulitermes flavipes; it was isolated from the Western pine wood (Pinus monticola Dougl.) decayed by the fungus Lenzites trabea (Esenther et al., 1961). The volatile 
Table 6: Common compounds present in decayed and healthy stems of cultivars TRI 2023, TRI 2027, TRI4042, TRI 4049

\begin{tabular}{|c|c|c|c|c|c|c|c|c|}
\hline \multirow[b]{3}{*}{ Compound } & \multicolumn{8}{|c|}{$\%$ Total } \\
\hline & \multicolumn{4}{|c|}{ Decayed stems } & \multicolumn{4}{|c|}{ Healthy stems } \\
\hline & $\begin{array}{c}\text { TRI } \\
2023\end{array}$ & $\begin{array}{c}\text { TRI } \\
2027\end{array}$ & $\begin{array}{c}\text { TRI } \\
4042\end{array}$ & $\begin{array}{c}\text { TRI } \\
4049\end{array}$ & $\begin{array}{c}\text { TRI } \\
2023\end{array}$ & $\begin{array}{c}\text { TRI } \\
2027\end{array}$ & $\begin{array}{c}\text { TRI } \\
4042\end{array}$ & $\begin{array}{c}\text { TRI } \\
4049\end{array}$ \\
\hline Terpenene 1-ol & 2.45 & 1.26 & 1.45 & 1.4 & & & & \\
\hline Beta terpineol & 0.96 & 0.51 & 0.64 & 0.54 & & & & \\
\hline Alpha terpineol & 3.22 & 1.7 & 2.3 & 1.71 & & & & \\
\hline n-dodecene & 1.78 & 0.58 & 0.55 & 0.67 & & & & \\
\hline 2-methoxy-4-vinylphenol & 2.05 & 1.76 & 1.28 & 2.36 & & & & \\
\hline $\mathrm{n}$ tridecane & 2.66 & 0.99 & 1.25 & 1.03 & & & & \\
\hline 1- Tetradecene (n-Tetra decene) & 3.15 & 0.96 & 2.2 & 1.21 & & & & \\
\hline Ethanone,1-(4-hydroxy-3-methoxy phenyl)- & 1.36 & 0.58 & 1.51 & 1.55 & & & & \\
\hline n-dodecanoic acid & 1.08 & 5.32 & 4.29 & 1.53 & & & & \\
\hline n-tertradecanoic acid & 1.55 & 5.24 & 4.82 & 3.55 & & & & \\
\hline 1,2-Benzenedicarboxylic acid, bis (2-methylpropyl) ester & 0.69 & 2.3 & 1.33 & 0.64 & & & & \\
\hline n-hexadecanoic acid & 12.47 & 12.1 & 14.2 & 20.4 & 11.01 & 16.2 & 6.7 & 1.45 \\
\hline 9,12-Octadecadienoic acid(Z,Z) & 9.76 & 9.58 & 6.74 & 15.6 & & & & \\
\hline 1,2-Benzenedicarboxlic acid,dicyclohexyl ester & 2.99 & 1.2 & 1.89 & 1.39 & & & & \\
\hline mono(2-ethylhexyl) phthalate & 8.76 & 2.61 & 9.7 & 3.91 & 27.77 & 56.62 & 82.2 & 72.8 \\
\hline
\end{tabular}

compounds linalool, linalool oxide, phenyl acetaldehyde, methyl salicylate, geraniol and trans 2-hexanal, which was reported in the bark of the young stems of tea was totally different from the decayed stems and healthy stems detected in the present study (Amarasinghe et al., 2007).

\section{CONCLUSION}

The results of the present study revealed that $n$-hexadecanoic acid and 9,12-octa decadienoic $(Z, Z)$ are the major chemical constituents of decayed tea stem volatiles in all four tea cultivars, and there were several minor compounds present (Tables 2 and 3). The comparison of the volatiles of the four tea cultivars indicated that fifteen volatile compounds were common in decayed stems of tea cultivars. The volatiles of healthy tea stems show mono(2ethylhexyl) phthalate $(27-82 \%)$ as the major constituent in healthy stems, and it is also present in decayed stems of cultivars but in small quantities $(<10 \%)$. The number of volatile compounds present in healthy tea stems were less than that in decayed tea stems. The Y-tube olfactometer bioassay results revealed that the alates of LCLWT were more attracted to the volatiles of decayed stems than that of the healthy tea stems. The results indicated that attractant effect of the volatile sample is not dependent on the tea cultivar. The present study suggests that gas chromatography electroantegram (GC-EAG) studies can be carried out to isolate and identify the attractant chemical compounds in the volatiles of decayed tea stems. Successful identification of the active compounds with standard chemicals would enable the formulation of attractants to develop a new environmentally friendly attractant-based bait trap. Successful development of the bait trap techniques holds potential to improve integrated pest management (IPM) strategies for LCLWT.

\section{REFERENCES}

1. Advisory Circular PM 3 (2003). Termite Control in Low Grown Tea, pp. 5. Tea Research Institute of Sri Lanka, Talawakelle.

2. Amarasinghe L.D., Sivanesan M., De Silva G., De Silva M.J. \& Abeysinghe I.S.B. (2007). Response of Xyleborus fornicatus Eichhoff to some volatile compounds identified from tea bark. Sri Lanka Journal of Tea Science 71(2): 63 - 74.

3. Balasooriya A. (1998). Study of wood rot in tea (Camellia sinensis) with special reference to that caused by Nemania diffusa (syn. Hypoxylon vesticum). PhD thesis, University of Peradeniya, Sri Lanka.

4. Cornelious M.L., Daigle D.J., Connick W.J., Parker A. \& Wunch K. (2002). Responses of Coptotermes formosanus and Reticulitermes flavipes (Isoptera: Rhinotermitidae) to three types of wood rot fungi cultured on different substrates. Journal of Economic Entomology 95(1): 121 - 128.

DOI: http://dx.doi.org/10.1603/0022-0493-95.1.121

5. Cranham J.E. (1966). Insects and mite pests of tea in Ceylon and their control. Monograph on Tea Production in Ceylon, no 6, pp. 75 - 85. Tea Research Institute, Talawakelle.

6. Dantanarayana W. \& Fernando S.N. (1970). Biology and control of the live wood termite of tea. Tea Quarterly 41: $34-52$. 
7. Dethier V.G., Brown L.B. \& Smith C.W. (1960). The designation of chemicals in terms of the responses they elicit from insects. Journal of Economic Entomology 53: $134-136$.

DOI: http://dx.doi.org/10.1093/jee/53.1.134

8. Esenther G.R., Allen T.C., Cassida J.E. \& Shenefelt R.D. (1961). Termite attractant from fungus-infected wood. Science 134: 50.

DOI: http://dx.doi.org/10.1126/science.134.3471.50

9. Getty G.M. \& Haverty M.I. (1998). Consumption of sound and decayed Ponderosa Pine and Douglas fir by Reticulitermes spp. (Isoptera: Rhinotermitidae) from Northern California. Journal of Economic Entomology 91(3): $650-654$.

DOI: http://dx.doi.org/10.1093/jee/91.3.650

10. Gunawardana N.E. \& Dissanayake S. (2000). Host attractants for the banana stem borer, Odoiporus longicollis (Coleoptera: Curculionidae): identification, electrophysiological activity and behavioural bioassay. Journal of the National Science Foundation of Sri Lanka 28(4): $231-242$.

11. Gunawardana N.E. \& Swarnakanthi M.N.A. (1995). Behavioural and electrophysiological responses of the coconut pest, Rynchophorus ferrugineus (Coleoptera: Curculionidae) to host non host and alternate host plant volatiles. Journal of the National Science Council of Sri Lanka 23(2): 63 - 70 .

12. Hoballah M.E.F., Tamo C. \& Turlings T.J. (2002). Differential attractiveness of induced odors emitted by eight maize varieties for the parasitoid Cotesia marginiventris: is quality or quantity important? Journal of Chemical Ecology 28: $951-958$

13. Holighaus G. \& Schütz S. (2006). Odours of wood decay as semiochemicals for Trypodendron domesticum L. (Col., Scolytidae). Mitteilungen der Deutschen Gesellschaft für allgemeine und angewandte Entomologie 15: 161 - 165.
Availableathttp://www.dgaae.de/files/dgaae/downloads/Mi tteilungen\%20der\%20DGaaE/Gesamtdokument\%202006. pdf Accessed on 25 March 2015

14. Nordlund D.A. \& Lewis W.J. (1976). Terminology of chemical releasing stimuli in intraspecific and interspecific interactions. Journal of Chemical Ecology 2: 211 - 220 DOI: http://dx.doi.org/10.1007/BF00987744

15. Paranagama P.A., Adhikari A.A.C.K., Abeywickrama K.P. \& Bandara K.A.N.P. (2002). Toxicity and repellent activity of Cymbopogon citrates (D.C) Stap F. and Murraya koenigii Sprang. against Callosobruchus maculates (F.) (Coleoptera; Bruchidae). Tropical Agricultural Research and Extension 5(1\&2): 22 - 28.

16. Samarasinghe S.M., Ahangama D., Kumar V. \& Vitarana S.I. (1999). Volatile and non volatile compounds of the host plant affecting behavior of the low country live wood termite (Glyptotermes dilatataus Bugnion \& Popoff) of tea. Tropical Agriculturist 11: 380 - 392.

17. Sands W.A. (1977). The role of termites in tropical agriculture. Outlook on Agriculture 9(3): 135 - 143.

18. Sivapalan P. \& Senaratna K.A.D.W. (1981). Some aspects of the biology of the tea termite Glyptotermes dilatatus. Tea Quarterly 50(3): 117 - 122.

19. Smythe R.V., Coppel H.C. \& Allen T.C. (1967). The response of Reticulitermes spp. and Zootermopsis angusticollis (Isoptera) to extracts from woods decayed by various fungi. Annals of the Entomological Society of America 60(1): 8 - 9. DOI: http://dx.doi.org/10.1093/aesa/60.1.8

20. Vitarana S.I. (1989). Feasibility of biological control of the live wood termite (Glyptotermes dialatatus) of tea in Sri Lanka. Sri Lanka Journal of Tea Science, Conference Issue, pp. $99-112$.

21. Vitarana S.I. \& Mohotti K.M. (2008). Management of tea termites. Hand Book on Tea (ed. A.K.N. Zoysa), $2^{\text {nd }}$ edition, pp. 231 - 240. Tea Research Institute of Sri Lanka, Talawakelle. 